Proceedings

\title{
A Study of Biodiversity of Russian Local Sheep Breeds Based on Pattern of Runs of Homozygosity ${ }^{+}$
}

\author{
Tatiana Deniskova ${ }^{1, *}$, Arsen Dotsev ${ }^{1}$, Henry Reyer ${ }^{2}$, Marina Selionova ${ }^{3}$, Klaus Wimmers ${ }^{2}$, Gottfried Brem ${ }^{1,4}$ and \\ Natalia Zinovieva ${ }^{1}$
}

Citation: Deniskova, T.; Dotsev, A.; Reyer, H.; Selionova, M.; Wimmers, K.; Brem, G.; Zinovieva, N. A Study of Biodiversity of Russian Local Sheep Breeds Based on Pattern of Runs of Homozygosity. 2021, 68, x. https://doi.org/10.3390/xxxxx

Published: date

Publisher's Note: MDPI stays neutral with regard to jurisdictional claims in published maps and institutional affiliations.

Copyright: (C) 2021 by the authors. Submitted for possible open access publication under the terms and conditions of the Creative Commons Attribution (CC BY) license (http://creativecommons.org/licenses/by/4.0/).
1 L.K. Ernst Federal Research Center for Animal Husbandry, Dubrovitsy, Podolsk Municipal District, Moscow Region, Podolsk 142132, Russia; arsendotsev@vij.ru (A.D.); gottfried.brem@vetmeduni.ac.at (G.B.); n_zinovieva@mail.ru (N.Z.)

2 Institute of Genome Biology, Leibniz Institute for Farm Animal Biology, Dummerstorf, Germany; reyer@fbn-dummerstorf.de (H.R.); wimmers@fbn-dummerstorf.de (K.W.)

3 Russian State Agrarian University-Moscow Timiryazev Agricultural Academy, Moscow 127550, Russia; m_selin@mail.ru

4 Institute of Animal Breeding and Genetics, University of Veterinary Medicine, Vienna, Austria

* Correspondence: horarka@yandex.ru; Tel.: +7-4967-65-11-63

† Presented at the 1st International Electronic Conference on Biological Diversity, Ecology and Evolution, 1531 March 2021; Available online: https://bdee2021.sciforum.net/.

Abstract: A rapid spreading of cosmopolite breeds leads to decrease of population sizes of Russian local sheep that consequently might result in their biodiversity loss. Estimation of the runs of homozygosity $(\mathrm{ROH})$ in local sheep genomes is an informative tool to address their current genetic state. In this work, we aimed to address the distribution of the $\mathrm{ROH}$ and to estimate genome inbreeding in Russian local sheep breeds based on SNP-genotyping. Medium-density SNP-genotypes of twenty-three local sheep breeds $(n=332)$ were obtained in our previous study. We used a consecutive runs method implemented in the R package "detectRUNS" to calculate $\mathrm{ROH}$ which were estimated for each animal and then categorized in the ROH length classes (1-2 Mb, 2-4 Mb, 4-8 Mb, $8-16 \mathrm{Mb},>16 \mathrm{Mb})$. The frequency of short $\mathrm{ROH}$ segments $(\leq 2 \mathrm{Mb})$ were the highest in all studied breeds (63.15-93.10\%). The longest segments $(>16 \mathrm{Mb})$ were the least frequent and were missing in four breeds. The genomic coefficients based on $\mathrm{ROH}$ estimation varied from medium (0.114) to low (0.035). Thus, we found that Russian local sheep breeds are characterized by a low level of genomic inbreeding.

Keywords: sheep; genetic diversity; SNPs; genomic inbreeding

\section{Introduction}

Genetic resources of Russian local sheep include breeds, which were specifically selected for wool and combined (wool and meat) production, and aboriginal breeds, which are adapted to extreme environments and from which all types of sheep products are used by local smallholders [1]. A rapid spreading of cosmopolite breeds leads to decrease of population sizes of Russian local sheep that consequently might result in their biodiversity loss.

Runs of homozygosity $(\mathrm{ROH})$ are numbers of homozygous loci that inbred progeny inherit from parents which originated from a common ancestor. Calculation of the length of $\mathrm{ROH}$ segments allows to find out whether inbreeding in the populations was recent or ancient [2,3]. Evaluation of genomic inbreeding coefficients based on $\mathrm{ROH}$ calculation is not determined by allelic frequencies, sampling procedures, and is considered as a robust measure for describing levels of inbreeding in the populations with missing pedigree information [4]. In this aspect, estimation of runs of homozygosity in genomes of livestock species is an informative tool to address their current genetic state [5]. 
In this work, we aimed to address the distribution of the $\mathrm{ROH}$ and to estimate genome inbreeding in Russian local sheep breeds based on medium-density SNP-genotyping data.

\section{Experiments}

\subsection{Materials and Methods}

Materials for this study included SNP-genotypes of twenty-two local sheep breeds ( $n$ =332) which were generated with OvineSNP50 BeadChip (Illumina, San Diego, CA, USA) in our previous research [6]. The SNP-profiles of the Romanov, Kuchugur and Baikal finefleeced breeds were not analyzed in the present study. The list of the studied breeds and sample sizes are presented in Table 1. The details on the relevant dataset including the sampling locations for each breed, the SNP quality control and the phylogenetic links between the breeds are available online at https:/gsejournal.biomedcentral.com/articles/10.1186/s12711-018-0399-5 (accessed on). The SNP-genotypes are available from the corresponding author on reasonable request.

Table 1. Values of inbreeding coefficient calculated based on $\mathrm{ROH}(\mathrm{FROH})$ in Russian local breeds.

\begin{tabular}{ccccc}
\hline Group & $\mathbf{n}^{\mathbf{1}}$ & FrOH_Mean ${ }^{2}$ & FroH_Min $^{3}$ & FroH_Max $^{4}$ \\
\hline Altay Mountain & 12 & $0.05 \pm 0.003$ & 0.04 & 0.07 \\
Andean Black & 16 & $0.077 \pm 0.008$ & 0.03 & 0.15 \\
Buubei & 17 & $0.05 \pm 0.007$ & 0.03 & 0.15 \\
Dagestan Mountain & 16 & $0.064 \pm 0.003$ & 0.05 & 0.09 \\
Edilbai & 17 & $0.046 \pm 0.002$ & 0.04 & 0.06 \\
Groznensk & 13 & $0.049 \pm 0.002$ & 0.04 & 0.06 \\
Kalmyk & 18 & $0.047 \pm 0.004$ & 0.03 & 0.11 \\
Karachaev & 16 & $0.049 \pm 0.002$ & 0.03 & 0.06 \\
Karakul & 21 & $0.054 \pm 0.002$ & 0.04 & 0.07 \\
Kuibyshev & 15 & $0.061 \pm 0.004$ & 0.05 & 0.1 \\
Kulundin & 13 & $0.07 \pm 0.003$ & 0.06 & 0.09 \\
Lezgin & 13 & $0.035 \pm 0.002$ & 0.03 & 0.05 \\
Manych Merino & 16 & $0.057 \pm 0.002$ & 0.04 & 0.08 \\
North Caucasian & 16 & $0.082 \pm 0.003$ & 0.06 & 0.11 \\
Russian Longhaired & 13 & $0.114 \pm 0.007$ & 0.08 & 0.18 \\
Salsk & 16 & $0.063 \pm 0.003$ & 0.04 & 0.09 \\
Soviet Merino & 14 & $0.056 \pm 0.001$ & 0.05 & 0.06 \\
Stavropol & 15 & $0.069 \pm 0.008$ & 0.04 & 0.16 \\
Tsigai & 16 & $0.05 \pm 0.003$ & 0.03 & 0.09 \\
Tushin & 11 & $0.05 \pm 0.005$ & 0.03 & 0.08 \\
Tuva & 13 & $0.043 \pm 0.002$ & 0.03 & 0.06 \\
Volgograd & 15 & $0.071 \pm 0.002$ & 0.06 & 0.08 \\
\hline
\end{tabular}

${ }^{1} \mathrm{n}$ - sample number; ${ }^{2} \mathrm{FROH} \_$Mean -inbreeding coefficient calculated based on ROH with a minimum length of $1 \mathrm{Mb} ;{ }^{3} \mathrm{FROH} \_\mathrm{Min}$

- minimum values of Froн estimations observed in individual animals within breeds; ${ }^{4}$ FroH_Max - maximum values of

Froн estimations observed in individual animals within breeds.

\subsection{Data Processing}

For ROH calculation, we used a window-free method for consecutive SNP-based detection [7] implemented in the R package "detectRUNS" [8]. One SNP with missing genotype and up to one possible heterozygous genotype was allowed in the run. The minimum ROH length was $1000 \mathrm{~kb}$.

$\mathrm{ROH}$ were estimated for each animal and then categorized in the corresponding $\mathrm{ROH}$ length classes: (1-2 Mb, 2-4 Mb, 4-8 Mb, $8-16 \mathrm{Mb},>16 \mathrm{Mb}$ ). The total number of identified $\mathrm{ROH}$ was calculated for each length category in each of the individuals of each breed. The 
mean sum of $\mathrm{ROH}$ was computed by adding up the length of all $\mathrm{ROH}$ for each individual in the sheep populations and then the results were averaged per breed population.

The genomic inbreeding coefficient based on $\mathrm{ROH}\left(\mathrm{F}_{\mathrm{ROH}}\right)$ was estimated as the sum of the length of all $\mathrm{ROH}$ per sheep as a proportion of the total autosomal SNP coverage $(2.44 \mathrm{~Gb})$.

\section{Results}

$\mathrm{ROH}$ were found on all autosomes in all Russian local sheep breeds. The genome coverage by ROH was higher on OAR1 (7.88-12.10\%), OAR $2(9.03-11.94 \%)$ and OAR3 $(6.28-11.42 \%)$, and lower on OAR20 (1.05-2.44\%) and OAR26 (1.06-2.24\%). ROH length and $\mathrm{ROH}$ number varied from $93.73 \pm 4.29 \mathrm{Mb}$ and 68 in the Lezgin breed to $301.69 \pm 19.71$ $\mathrm{Mb}$ and 117 in the Russian Longhaired breed. The individual minimum was found in the Lezgin breed (68.16 Mb and 54), while maximum was detected in the Russian Longhaired breed (469.99 $\mathrm{Mb}$ and 138).

Figure 1 shows the distribution of the $\mathrm{ROH}$ segments in length classes in Russian local sheep breeds. The frequency of short $\mathrm{ROH}$ segments $(\leq 2 \mathrm{Mb})$ was the highest in all studied breeds and varied from $63.15 \%$ in the Russian Long haired breed to $93.10 \%$ in the Lezgin breed. The Tushin breed had the minimum of the $\mathrm{ROH}$ segments of $2-4 \mathrm{Mb}$ length class $(6.09 \%)$, while the Russian Longhaired breed had the maximum $(24.62 \%)$. The frequencies of the $\mathrm{ROH}$ segments within length class $(4-8 \mathrm{Mb})$ varied from $0.57 \%$ in the Lezgin breed to $10.01 \%$ in the Russian Longhaired breed. Long ROH segments (8-16 Mb) ranged from $0.19 \%$ in the Tuva breed to $3.46 \%$ in the Andean breed. The longest $\mathrm{ROH}$ segments $(>16 \mathrm{Mb})$ were the least frequent $(0.07-1.22 \%)$ and were missing in four breeds.

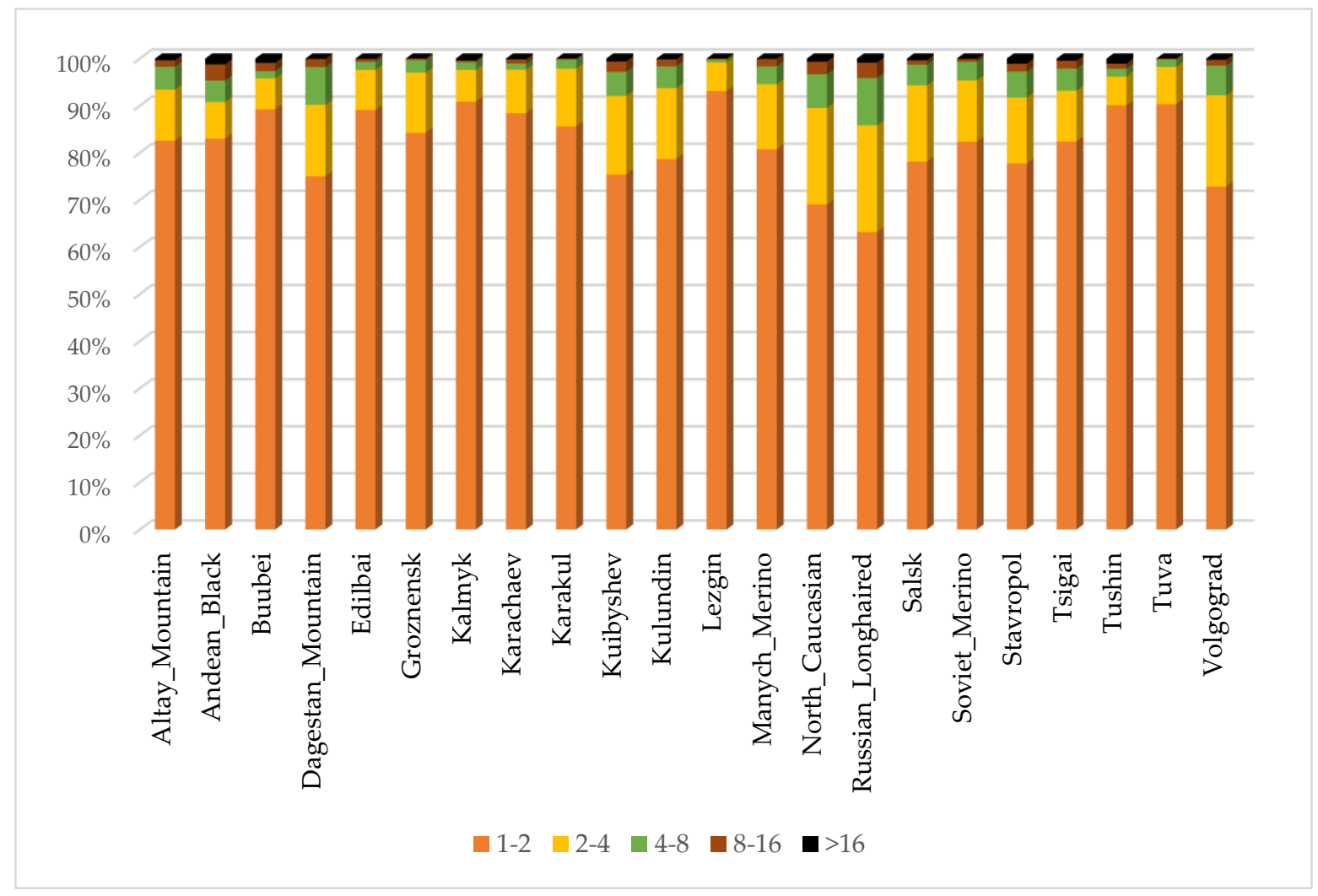

Figure 1. Distribution of the runs of homozygosity in length classes (1-2 Mb, 2-4 Mb, 4-8 Mb, 8-16 Mb, >16 Mb) in Russian local sheep breeds.

Estimates of inbreeding coefficient calculated based on $\mathrm{ROH}$ in Russian local breeds are given in Table 1 . The values of genomic inbreeding coefficient varied from medium to 
low. The minimum $\mathrm{F}_{\mathrm{roH}}$ was calculated in the Lezgin breed $\left(\mathrm{F}_{\mathrm{roH}}=0.035\right)$ and the maximim was detected in the Russian Longhaired breed $\left(\mathrm{F}_{\mathrm{ROH}}=0.114\right)$. The range of individual $\mathrm{F}_{\mathrm{ROH}}$ variability was more noticeable in several breeds including Andean Black ( $\mathrm{F}_{\mathrm{ROH}}$ from 0.03 to 0.15 ), Buubei (FroH from 0.03 to 0.15 ), Kalmyk (FroH from 0.03 to 0.11 ), North Caucasian (Froн from 0.06 to 0.11 ), Russian Longhaired ( $\mathrm{F}_{\mathrm{roH}}$ from 0.08 to 0.18 ), and Stavropol (FroH from 0.04 to 0.16 ).

\section{Discussion}

There are several approaches to address biodiversity and its dynamics in the populations of livestock species: effective population size, heterozygosity and runs of homozygosity [9]. In our previous study, we calculated and analyzed effective population sizes and heterozygosity to unlock current state of genetic diversity in Russian local sheep breeds [6]. Nonetheless, estimation of runs of homozygosity is a useful tool to reveal the presence of long-term inbreeding in livestock populations [3].

A prevalence of short $\mathrm{ROH}$ segments revealed in Russian local sheep breeds are compatible with the relevant patterns detected in Swiss [4] and Italian local sheep breeds [10] as well as in commercial sheep breeds including Charollais, Suffolk, Texel [11], Border Leicester, Merino, and Poll Dorset [9].

The average values of $\mathrm{ROH}$ length calculated in our study were higher than those obtained in commercial sheep breeds (93.73-301.69 Mb versus 92.61-128.31 Mb [11]/94.88$126.06 \mathrm{Mb}$ [9], respectively). Maximum individual $\mathrm{ROH}$ length values estimated in our study $(400$ and $469.99 \mathrm{Mb})$ were close to those obtained in Australian populations of Border Leicester, Merino, and Poll Dorset breeds (427.2, 410.5 and 396.45 Mb) [9].

Mean FroH varied from 0.016 to 0.099 in Italian local breeds including Valle del Belice and Comisana [10] and from 0.022 to 0.153 in Swiss local breeds [4]. These estimates are compatible with the Froн variation detected in Russia local sheep breeds.

The highest values of genome coverage by $\mathrm{ROH}$ segments and the maximum inbreeding coefficient calculated based on $\mathrm{ROH}$, which were found in the Russian Longhaired breed, might correspond to the small population size (1400 heads at the end of 2019) [12] and to using of a limited number of sires.

\section{Conclusions}

Here, we presented a detailed analysis of pattern of distribution of the runs of homozygosity in major Russian local sheep breeds based on 50K SNP-profiles. Our findings provide an evidence of a low genomic inbreeding in local sheep populations (except for the Russian Longhaired). The study results provide useful information to design conservation programs for local genetic resources of sheep.

Author Contributions: N.Z., G.B. and T.D. conceived and designed the experiments; T.D. and H.R. performed the experiments; A.D. and H.R. analyzed the data; M.S. and K.W. contributed reagents/materials/analysis tools; T.D. wrote the paper.

\section{Institutional Review Board Statement:}

\section{Informed Consent Statement:}

Data Availability Statement:

Acknowledgments: The study was supported by Ministry of Science and Higher Education of the Russian Federation within theme No. 0445-2019-0024.

Conflicts of Interest: The authors declare no conflict of interest. Ministry of Science and Higher Education of the Russian Federation had no role in the design of the study; in the collection, analyses, or interpretation of data; in the writing of the manuscript, and in the decision to publish the results. 


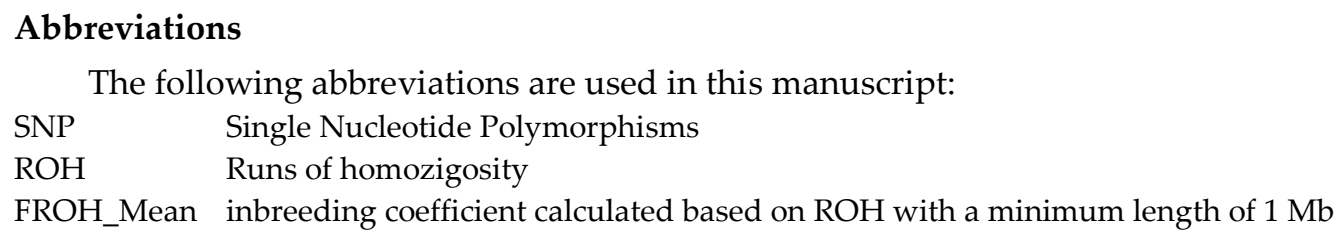

\section{References}

1. Dunin, I.M.; Dankvert, A.G. Spravochnik porod i tipov sel skokhozyastvennykh zhivotnykh, razvodimykh v Rossiiskoi Federatsii. VNIIPLEM: Moskva, Russia, 2013. (In Russian)

2. McQuillan, R.; Leutenegger, A.L.; Abdel-Rahman, R.; Franklin, C.S.; Pericic, M.; Barac-Lauc, L. Runs of homozygosity in European populations. Am. J. Hum. Genet. 2008, 83, 359-372. Available online: https://www.cell.com/ajhg/fulltext/S0002-929700445X (accessed on 10 February 2021). doi:/10.1016/j.ajhg.2008.08.007.

3. Curik, I.; Ferenčaković, M.; Solkner, J. Inbreeding and runs of homozygosity: A possible solution to an old problem. Livest. Sci. 2014, 166, 26-34, doi:10.1016/j.livsci.2014.05.034.

4. Signer-Hasler, H.; Burren, A.; Ammann, P.; Drögemüller, C.; Flury, C. Runs of homozygosity and signatures of selection: A comparison among eight local Swiss sheep breeds. Anim. Genet. 2019, 50, 512-525. Available online: https://onlinelibrary.wiley.com/doi/abs/10.1111/age.12828 (accessed on 12 February 2021). doi:10.1111/age.12828.

5. Sölkner, J.; Ferenčaković, M.; Gredler, B.; Curik, I. Genomic metrics of individual autozygosity, applied to a cattle population, In Proceedings of the 61st Annual Meeting of the European Association of Animal Production, Heraklion, Crete Island, Greece, 23-27 August 2010; Wageningen Academic Publishers: Wageningen, The Netherlands, 2010; 306p.

6. Deniskova, T.E.; Dotsev, A.V.; Selionova, M.I.; Kunz, E.; Medugorac, I.; Reyer, H.; Wimmers, K.; Barbato, M.; Traspov, A.A.; Brem, G.; et al. Population structure and genetic diversity of 25 Russian sheep breeds based on whole-genome genotyping. Genet. Sel. Evol. GSE 2018, 50, 29. Available online: https://gsejournal.biomedcentral.com/articles/10.1186/s12711-018-0399-5 (accessed on 10 February 2021). doi:10.1186/s12711-018-0399-5.

7. Marras, G.; Gaspa, G.; Sorbolini, S.; Dimauro, C.; Ajmone-Marsam, P.; Valentini, A.; Williams, J.L.; Macciotta, N.P. Analysis of runs of homozygosity and their relationship with inbreeding in five cattle breeds farmed in Italy. Anim. Genet. 2014, 46, 110121. Available online: https://onlinelibrary.wiley.com/doi/abs/10.1111/age.12259 (accessed on 10 February 2021). doi:10.1111/age.12259.

8. Cran.R-project.org: detectRUNS: Detect Runs of Homozygosity and Runs of Heterozygosity in Diploid Genomes. Available online: https://cran.r-project.org/web/packages/detectRUNS/index.html (accessed on 25 January 2021).

9. Al-Mamun, H.A.; Clark, S.A.; Kwan, P.; Gondro, C. Genome-wide linkage disequilibrium and genetic diversity in five populations of Australian domestic sheep. Genet. Sel. Evol. GSE 2015, 47, 90. Available online: https://gsejournal.biomedcentral.com/articles/10.1186/s12711-015-0169-6 (accessed on 12 February 2021). doi:10.1186/s12711-015-0169-6.

10. Mastrangelo, S.; Ciani, E.; Sardina, M.T.; Sottile, G.; Pilla, F.; Portolano, B.; Bi.Ov. Ita Consortium. Runs of homozygosity reveal genome-wide autozygosity in Italian sheep breeds. Anim. Genet. 2018, 49, 71-81. Available online: https://onlinelibrary.wiley.com/doi/abs/10.1111/age.12634 (accessed on 12 February 2021). doi:10.1111/age.12634.

11. Purfield, D.C.; McParland, S.; Wall, E.; Berry, D.P. The distribution of runs of homozygosity and selection signatures in six commercial meat sheep breeds. PLoS ONE 2017, 12, e0176780. Available online: https://journals.plos.org/plosone/article?id=10.1371/journal.pone.0176780 (accessed on 12 February 2021).

12. Dunin, I.M.; Amerhanov, H.A.; Safina, G.F.; Grigoryan, L.N.; Hatataev, S.A.; Hmelevskaya, G.N.; Pavlov, M.B.; Stepanova, N.G. Ezhegodnik po Plemennoj Rabote v Ovcevodstve i Kozovodstve v Hozyajstvah Rossijskoj Federacii (2019 god). FGBNU Vserossiiskii Nauchno-Issledovatelskii Institut Plemennogo Dela Lesnye Poliany: Moskva, Russia, 2019. (In Russian) 